\title{
o Compadre Governador: redes de compadrio em Vila Rica de fins do século XVIII
}

\author{
Renato Pinto Venâncio \\ UFOP / Pesquisador do CNPq \\ Maria José Ferro de Sousa \\ UFOP \\ Maria Teresa Gonçalves Pereira \\ UFOP
}

Resumo

Analisamos neste artigo as relações políticas e sociais formalizadas no sacramento de batismo entre os membros da elite vilarriquenha, no período de 1777 1789. Para tanto, escolhemos os registros de batismo da paróquia de Nossa Senhora do Pilar do Ouro Preto e de suas capelas filiais, como testemunhos do estabelecimento e renovação dos laços de compadrio.

Palavras-chave: Política; Compadrio; Minas Gerais.

\begin{abstract}
We analyze in this study the political and social hierarchic relations, recognized in the baptism sacrament established by Vila Rica de Ouro Preto (Minas Gerais, Brazil) society partners from 1770-1789. To do this we chose the baptism certificates of the Our Lady of Pilar Church and their branch Chapels as testimony of the godparentage relations established and renovated at the baptisms. Keywords: Politics; Compadrio; Minas Gerais.
\end{abstract}

Propomos neste artigo uma análise dos laços políticos e sociais estabelecidos através do 'sacramento do batismo' entre membros da elite de Vila Rica. Nessa pesquisa, exploramos como fonte primária a documentação da $\mathrm{Ma}$ triz de Nossa Senhora do Pilar de Ouro Preto e de suas capelas filiais. ${ }^{1} \mathrm{Tal}$ paróquia, junto a de Nossa Senhora da Conceição de Antônio Dias, compunha o espaço urbano local. Do conjunto documental investigado, selecionamos os registros compreendidos entre 1777 e 1789, recorte cronológico que privilegia a década anterior à Inconfidência Mineira, movimento político cuja repressão gerou rica fonte documental a respeito dos membros da elite minei- 
ra, possibilitando assim uma análise mais aprofundada do que em relação a outros períodos.

Através de estudos de casos, procuramos mostrar a diversidade dos laços de compadrio, assim como procuramos preencher uma lacuna no que diz respeito às pesquisas referentes ao tema. Conforme revelam levantamentos bibliográficos, as análises da escolha de padrinhos do período colonial quase sempre se restringem à população escrava. ${ }^{2}$ As investigações sobre compadrio na população livre são $\operatorname{raras}^{3}$ e, no que diz respeito às elites políticas, só muito recentemente começaram a ser realizadas. ${ }^{4}$

Nossa hipótese central é a de que, na sociedade da época, a noção de 'prestígio' vinculava-se à capacidade de dispor de recursos (fossem eles pessoais ou do aparelho de Estado), gerando assim uma 'economia de favores', de dom e contra-dom; em outras palavras, de reciprocidade social envolvendo desiguais. Ao benfeitor cabia conceder e ao beneficiado cabia ser fiel, não sendo esse gesto visto como um desvio da 'norma', mas sim como sua corporificação.

Nesse contexto, a noção de 'amizade desigual', que subordinava a reciprocidade ao respeito à hierarquia social, tornava-se o elemento legitimador das relações de poder internas ou externas aos grupos sociais. No caso do compadrio, tais vínculos eram ainda mais intensos, pois geravam laços de parentesco para o resto da vida - tanto na relação padrinho-afilhado quanto na de compadre-compadre. Nesse sentido, é possível afirmar que o compadrio consistia em um dos elementos de estruturação das redes sociais que organizavam a vida cotidiana.

Através da análise da trajetória de quatro membros da elite de Vila Rica - dois deles com interesses enraizados localmente e dois deles altos funcionários reinóis, que permaneceram pouco tempo na capital mineira —, identificamos comportamentos diversos em termos de relações de compadrio, os quais acreditamos corresponder a inserções diferenciadas e típicas em termos de grupo de interesse local e grupo de interesse metropolitano.

\section{COMPADRIO E SALVAÇÃO DA ALMA}

Segundo as Constituições Primeiras do Arcebispado da Bahia, de $1707,{ }^{6}$ o batismo era, para o cristão, a "porta de entrada" na Igreja Católica e a oportunidade da salvação da alma. Quem não o recebesse ficava impedido de alcançar os demais sacramentos. A celebração da cerimônia requeria que "Matrizes, Capelas filiais, Ermidas e Oratórios” estivessem aparelhados com pia 
batismal "decente, água natural, santos óleos e paramentos das quatro cores"? O sacramento deveria ser ministrado pelo pároco, ou por outro eclesiástico, desde que tivesse a devida licença. Porém, quando o batizando corria risco de vida, o ato religioso também podia ser administrado em casa, pela parteira licenciada ou por qualquer outra pessoa, desde que houvesse a intenção de fazê-lo segundo os princípios da Igreja, proferindo as palavras: "Eu te baptizo em nome do Padre, e do Filho, e do Espírito Santo".

Em certo sentido, o sacramento significava para a criança a passagem do mundo dominado pelas mulheres para o mundo dominado pelos homens. ${ }^{8}$ Após o ato sacramental, o padre elaborava o assento de batismo em um livro competente, registrando a data do batismo e do nascimento do bebê, assim como o nome do templo, o nome da criança, sua idade, ${ }^{9}$ legitimidade, condição social e cor; registravam-se também os nomes dos pais e dos padrinhos e suas respectivas condições sociais (livres, escravos e forros); por fim, o padre eventualmente anotava o nome da rua ou da freguesia de domicílio dos pais e padrinhos. Como se vê, os registros paroquiais constituem um magnífico acervo de informações a respeito dos mais diversos aspectos do cotidiano colonial, sendo surpreendente sua tímida exploração, quase sempre restrita à evolução demográfica das comunidades locais.

Contendo inúmeras informações, não é surpreendente que os 'livros paroquiais' tenham sido visto com bons olhos pelo Estado monárquico. Numa sociedade marcada por elevado número de iletrados, o documento constituía um dos raros testemunhos escritos que provavam o vínculo familiar e a condição social dos indivíduos. Os processos matrimoniais dele dependiam. Através das atas batismais provava-se a posse de um escravo; forros em pia batismal, por sua vez, utilizavam esse testemunho para demonstrar a própria liberdade. Na identificação de herdeiros ou na elaboração de genealogias, destinadas a demonstrar 'pureza de sangue', também não se podia prescindir da ata de batismo. O documento era um identificador pessoal e social, como é possível observar neste exemplo:

Aos vinte e nove dias do mês de junho de mil setecentos e oitenta e quatro anos, no oratório de Dona Leonor Luísa de Portugal, desta freguesia de Nossa Senhora do Pilar de Vila Rica de Ouro Preto, por concessão do Excelentíssimo e Reverendíssimo Senhor Bispo deste Bispado, o Reverendo Doutor Manuel Joaquim Pereira Coimbra, Presbítero Secular, com licença do Reverendo Vigário atual Vidal José do Vale, batizou e pôs os santos óleos a Maria filha legítima do Alferes José Antônio de Melo, natural da Vila de São João d'el Rei deste Bispado; 
e de sua mulher Dona Josefa Fidelis de Molina e Velasco, natural da cidade do Rio de Janeiro, neta pela parte paterna do Doutor Antônio José de Melo, natural do Patriarcado de Lisboa, e de sua mulher Dona Joana Fidelis da Silva, natural da cidade do Rio de Janeiro, e pela materna do Coronel José Luís Saião, natural de Lisboa, e de sua mulher Dona Catarina Molina de Velasco, natural do Rio de Janeiro. Foram Padrinhos: o Ilustríssimo e Excelentíssimo Luís da Cunha Menezes, Governador e Capitão General desta Capitania de Minas, e Dona Leonor Luísa de Portugal, todos desta freguesia, de que fiz este assento.

O Coadjutor Antônio Ribeiro de Azevedo..$^{10}$

O compadrio consistia em uma relação nascida no sacramento do batizado e registrada nos livros paroquiais. Por se tratar de um "renascimento espiritual”, os batizandos deveriam dispor de novo vínculo filial, agora definido através dos "pais espirituais". Desde a Idade Média, a Igreja esforçou-se para que esse preceito fosse cumprido de forma estrita. No entanto, a possibilidade de se multiplicar laços de parentesco espiritual, fortalecendo a linhagem ou o grupo doméstico, muitas vezes levava à multiplicação do número de padrinhos. Em casos extremos, registrou-se o conjunto dos membros de uma confraria, ou até mesmo dos habitantes de uma cidade, sendo escolhidos como "padrinhos" de uma única criança. ${ }^{11}$ O Concílio de Trento (1545-1563) lutou contra tal prática, reiterando que deveria haver apenas um padrinho e uma madrinha, selecionados na comunidade de católicos. Abria-se exceção apenas para os casos de se escolher compadres santos ou santas. Aliás, não são raros os assentos de batismo coloniais que trazem "Nossa Senhora" como madrinha, gesto provavelmente inspirado na busca de proteção à parturiente.

O sacramento implicava a constituição de laços com uma nova família espiritual, que influenciava diretamente a carnal. Era usual, no momento do batismo, o pároco fazer algumas perguntas aos padrinhos, que as respondiam em alto e bom tom, transformando-os em fiadores públicos daqueles por quem respondiam. Tal compromisso significava privilégios e deveres de ambas as partes, os quais eram reconhecidos através da obediência, fidelidade e reverência do afilhado, em contrapartida às múltiplas responsabilidades dos padrinhos.

\section{UM INVENTÁRIO DAS DIFERENÇAS}

Durante o século XVIII, Minas Gerais atraiu um grande contingente de imigrantes. Paralelamente a esse fluxo espontâneo, de gente em busca de ri- 
queza, havia a migração forçada dos escravos, pelo tráfico atlântico. Esse amálgama populacional, como em outras partes da América portuguesa, gerou uma sociedade plural no sentido cultural, econômico e social. Apesar do declínio da mineração, a região mineira continuou bastante populosa: em 1776, o número de habitantes, excluindo os índios, era superior a 300 mil habitantes, o que representava cerca de 20 por cento da população colonial — o maior contingente reunido em uma única capitania. ${ }^{12}$

Para conhecer essa população, os historiadores utilizam, de longa data, os assentos de batismos, casamento e óbitos, que, conforme indicamos, permitem estudos quantitativos e qualitativos. No presente trabalho, pretende-se mostrar que os assentos batismais possibilitam o conhecimento de formas de sociabilidade da elite. Tal segmento é aqui entendido nos moldes da nobreza civil e política lusitana. Conforme assinalam estudiosos do tema, trata-se de uma camada que se destacava não só pela riqueza, como também "pelos cargos, e postos da República" que ocupavam, e pelos "feitos gloriosamente obrados de os constituir nos princípios da nobreza de sorte que verdadeiramente se não pode dizer deles que são nobres, se não que o começam de ser”."13

Tendo em vista tal critério, é possível afirmar que a elite mineira era formada não só por grupos que se enriqueceram graças ao ouro ou ao comércio de longa distância, como também por representantes da Coroa: governadores, contratadores, desembargadores, ouvidores etc. Tratava-se, na realidade, de uma hierarquia complexa, pois envolvia não só a situação econômica ou política, como também a 'qualidade' da pessoa, identificada simbolicamente através de sua condição social (livre ou forra); sua cor (branca, parda, cabra ou negra); sua condição de nascimento (legítima, ilegítima ou abandonada); sua naturalidade (portuguesa, colonial ou africana); e sua dignidade ou título nobiliárquico civil, eclesiástico e militar, expressos nas formas de tratamento: Ilustríssimo, Reverendíssimo, Dom, Dona, Capitão, Tenente, Sargento Mor etc.

Conforme mencionamos, procuramos analisar o comportamento de quatro membros da elite de Vila Rica colonial. Quem eram, porém, esses indivíduos? Na Tabela 1 indicamos seus nomes e ocupações. O primeiro deles é João Rodrigues de Macedo, natural de Coimbra, e que teria chegado a Minas Gerais por volta de 1775, com 30 ou 35 anos de idade, quando então, através da arrematação de contratos de cobrança de impostos, acumulou vasta fortuna, chegando a ser definido "como o homem mais rico da capitania". ${ }^{14}$ 
Tabela 1

Padrinhos da paróquia de Nossa Senhora do Pilar de Vila Rica, 1777-1789

\begin{tabular}{lcccc}
\hline Padrinhos & Período & $\begin{array}{c}\text { Condição social } \\
\text { dos padrinhos }\end{array}$ & $\begin{array}{c}\text { Número de } \\
\text { crianças apadrinhadas }\end{array}$ & $\begin{array}{c}\text { Média anual } \\
\text { de afilhados }\end{array}$ \\
\hline $\begin{array}{l}\text { João Rodrigues } \\
\text { de Macedo }\end{array}$ & $1777-89$ & Contratador & 15 & 1,2 \\
\hline $\begin{array}{l}\text { Francisco de P. F. } \\
\text { de Andrada }\end{array}$ & $1780-84$ & Tenente Coronel & 8 & 2,0 \\
\hline $\begin{array}{l}\text { Rodrigo José } \\
\text { de Menezes }\end{array}$ & $1780-83$ & Governador & 11 & 3,6 \\
\hline $\begin{array}{l}\text { Luís da Cunha } \\
\text { Menezes }\end{array}$ & $1783-87$ & Governador & 23 & 5,7 \\
\hline
\end{tabular}

Fonte: Banco de Dados da Paróquia de Nossa Senhora do Pilar do Ouro Preto. Casa dos Contos.

Tratava-se de personagem com interesses enraizados localmente. Durante o processo da Inconfidência, João Rodrigues de Macedo livrou-se da acusação de conspirar contra a Coroa portuguesa, conseguindo permanecer em Minas Gerais até o final da vida. Na referida tabela selecionamos um período específico da vida do contratador. Tal recorte cronológico privilegia os anos em que o estabelecimento de laços de compadrio atingiu as médias mais elevadas.

O segundo nome da tabela é o de Francisco de Paula Freire de Andrada, nascido no Rio de Janeiro, em 1756, e filho ilegítimo do $2^{\circ}$ Conde de Bobadela (Gomes Freire de Andrada - governador da capitania mineira em vários períodos do século XVIII: 1735-1736, 1737-1752 e 1759-1763). Aos 12 anos, Francisco de Paula Freire de Andrada entrou para vida militar e, aos 24 anos, tornou-se "Tenente Coronel do Regimento de Cavalaria das Minas", casando-se, por essa época, em Vila Rica. Para se ter noção da sua riqueza, basta mencionar que o dote da esposa foi de doze contos de réis, o que permitia, no mínimo, a compra de 100 a 120 escravos, valor que foi reunido à riqueza pessoal do esposo, dando origem a uma das famílias mais ricas da capitania. ${ }^{15}$

Apesar dessa fortuna, Francisco de Paula Freire de Andrada não escapou à repressão política que se seguiu à Inconfidência, vindo a falecer no exílio africano. O recorte cronológico referente a esse personagem também privilegia o período mais intenso de estabelecimento de laços de compadrio.

O terceiro nome indicado na Tabela 1 é o de D. Rodrigo José de Menezes, governador de Minas Gerais entre 1780 e 1783 . Proveniente de uma fa- 
mília aristocrática, das mais importantes de Portugal, D. Rodrigo nasceu por volta de 1750, assumindo o governo de Minas com cerca de 30 anos. Tratavase de um "modelo de mando" do Império português $;{ }^{16}$ homem ilustrado, percebeu a crise econômica que grassava na capitania e lutou pela liberação da fabricação de ferro e pelo livre estabelecimento de engenhos de açúcar e aguardente, até então proibidos. ${ }^{17}$

O último personagem da Tabela 1 é Luís da Cunha Menezes, também natural de Portugal, e que governou Minas entre 1783 e 1788. Ao contrário do predecessor, era muito mal afamado, tendo sido acusado de opressor dos povos mineiros e caracterizado como o tirânico "Fanfarrão Minésio", na poesia de Cláudio Manoel da Costa.

A primeira constatação de nossa pesquisa diz respeito ao elevado número de crianças apadrinhadas. ${ }^{18}$ D. Luís da Cunha Menezes, por exemplo, apesar de ter permanecido menos de cinco anos em Vila Rica, aceitou ser padrinho de 23 crianças, o que equivalia a 5 ou 6 apadrinhamentos por ano. D. Rodrigo José de Menezes não fica muito atrás: em três anos, apadrinhou 11 crianças. João Rodrigues de Macedo, num espaço de doze anos, abençoou 15 afilhados, média um pouco superior a uma ocorrência por ano; o tenente coronel Francisco de Paula Freire de Andrada apresenta um índice de compadrio ainda mais elevado: o dobro do anterior.

Tratar-se-ia de comportamentos excepcionais? Acreditamos que não. A análise do comportamento dos demais governadores mostra que a prática de compadrio com autoridades era recorrente. Durante a segunda metade do século XVIII e início do século XIX, é possível mesmo afirmar que esse traço foi típico, embora variasse de intensidade. Assim, paralelamente aos exemplos mencionados, temos, na referida paróquia do Pilar, os seguintes casos de governadores padrinhos: D. Luis Diogo Lobo da Silva, entre 1763 e 1768, apadrinhou 7 crianças; D. Antonio de Noronha, entre 1775 e 1780, aceitou apadrinhar 15 meninos e meninas; D. Bernardo José de Lorena, entre 1797 e 1803, foi responsável pelo mesmo gesto em relação a sete crianças e, por último, Pedro Maria de Athaíde e Melo, entre 1803 e 1810, foi padrinho de cinco recémnascidos.

Nossa amostragem selecionou os casos de governadores que, em termos de médias anuais, mais estabeleceram laços de compadrio. A criação desse laço social, por razões óbvias, era algo desejado. Um testemunho do início do século XIX revela como era feito o convite oficial. Em 1814, D. Manoel de Portugal, então governador de Minas Gerais, recebeu uma carta com o seguinte teor: 
No mesmo dia em que tive por certa a feliz chegada de V. Exª a Capitania do mais venturoso Governo, eu tive a ousadia de enviar a V. $\mathrm{Ex}^{\mathrm{a}}$ as minhas humildes demonstrações de obediência e contentamento, não conforme os desejos do mais atento e submisso súdito, mas sim pelo modo mais sincero e despido de toda a energia, porque seguindo a minha curta idéia não tenho luzes com que possa decantar parabéns em dia tão brilhante, devidos à sempre Respeitável Pessoa de V. Ex a e mesma Capitania, e portanto como mais interessado a mim os dou pela distinta honra em que me tenho dispor, que como fiel súdito e criado obedeço e respeito a V. Exa . Agora porém, que, seguindo as obrigações de Pai de família devo felicitar aos meus filhos; me atrevo revestido de respeito, o mais considerável a apresentar a V. Ex ${ }^{\mathrm{a}} \mathrm{o}$ quinto, e recém-nascido, para que, dignando-se V. Exa de aceitar o novo criado, junto a mim, que tenho a honra de ser o mais fiel de V. Ex $x^{a}$, possamos honrarmos com a graça que humilde suplico a V. $\mathrm{Ex}^{\mathrm{a}} \mathrm{de}$ uma Procuração para levá-lo à Pia Batismal; a qual constituirá toda a minha satisfação, honra e prazer... ${ }^{19}$

Como é possível perceber, o convite ocorria assim que o governador assumia o posto, não resultando necessariamente da cristalização de um convívio social. A maior ou menor aceitação do laço de compadrio, por parte dos governadores, dependia de circunstâncias políticas do momento. Não por acaso, Luís da Cunha Menezes, retratado pela historiografia como um dos governantes de pior reputação de Minas Gerais colonial, aceitou grande número de afilhados. Porém, o testemunho citado confirma "que qualquer desejo por parte da Coroa portuguesa para manter as autoridades reais independentes dos interesses locais foi subvertido pelo compadrio". ${ }^{20}$

Aqueles que tinham interesses econômicos e familiares enraizados em Vila Rica, como eram os casos dos referidos contratador e tenente coronel, surpreendentemente apadrinharam bem menos crianças do que alguns governadores - constatação que reafirma a importância do compadrio como indicador das hierarquias de poder existentes na sociedade.

A diversidade dos vínculos gerados pelo compadrio também pode ser percebida mediante o perfil social dos pais das crianças. Nos 57 casos analisados, não se identificou nenhum escravo, sugerindo assim, por parte da elite, um comportamento distante do estereótipo do 'paternalismo senhorial'. No que diz respeito ao status dos pais livres, observam-se, entre as autoridades metropolitanas e a elite colonial, sensíveis diferenças. 
Tabela 2

Pais com títulos sociais na paróquia de N. Sra. do Pilar de Vila Rica, 1777-1789

\begin{tabular}{lcccc}
\hline Padrinhos & $\begin{array}{c}\text { Condição social } \\
\text { dos padrinhos }\end{array}$ & $\begin{array}{c}\text { Número de } \\
\text { crianças batizadas }\end{array}$ & $\begin{array}{c}\text { Número de pais } \\
\text { das crianças } \\
\text { com títulos }\end{array}$ & $\begin{array}{c}\text { \% de pais } \\
\text { das crianças } \\
\text { com títulos }\end{array}$ \\
\hline $\begin{array}{l}\text { João Rodrigues } \\
\text { de Macedo }\end{array}$ & Contratador & 15 & 2 & 13,3 \\
\hline $\begin{array}{l}\text { Francisco de P. F. } \\
\text { de Andrada }\end{array}$ & Tenente Coronel & 8 & 3 & 37,5 \\
\hline $\begin{array}{l}\text { Rodrigo José } \\
\text { de Menezes }\end{array}$ & Governador & 11 & 82,2 \\
\hline $\begin{array}{l}\text { Luís da Cunha } \\
\text { Menezes }\end{array}$ & Governador & 23 & 23 & 100,00 \\
\hline
\end{tabular}

Fonte: Banco de Dados da Paróquia de Nossa Senhora do Pilar do Ouro Preto. Casa dos Contos.

Na Tabela 2, indicamos o resultado do levantamento da titulação ('doutor', 'militar' etc.) dos pais das crianças. Os governadores condicionavam a aceitação do apadrinhamento à titulação do compadre ou então dos avós da criança, conforme ocorreu com Maria e José, filhos respectivamente de Antonio Agostinho Lobo Leite Pereira e de José Antonio de Melo, cujos ascendentes imediatos possuíam títulos de 'coronel' e 'doutor'. O mesmo não se pode afirmar em relação ao contratador e ao tenente coronel, bem mais tolerantes frente aos compadres não-titulados, havendo até mesmo casos, como o de João de Almeida e Souza, apresentado como 'cigano' - grupo social vinculado ao contrabando - , e o de Manuel Luís, registrado na ata batismal sem sobrenome - dado indicador de uma origem social humilde.

A Tabela 3 reafirma o comportamento aqui constatado. Nela observamos casos de compadrio com "pais incógnitos". Essas ocorrências diziam respeito aos filhos nascidos de relações pré ou extraconjugais. Embora tais arranjos fossem relativamente correntes na sociedade da época ${ }^{21}$ - o Tenente Coronel Freire de Andrada era, ele mesmo, fruto de um deles - , parece ter havido atitudes bastante distintas entre os membros da elite. Os governadores não aceitaram apadrinhar criança alguma que tivesse nascido fora de famílias legalmente constituídas; o contratador e o tenente coronel adotavam um comportamento mais flexível. 
Tabela 3

Pais “incógnitos” na paróquia de N. Sra. do Pilar de Vila Rica, 1777-1789

\begin{tabular}{lcccc}
\hline Padrinhos & $\begin{array}{c}\text { Condição social } \\
\text { dos padrinhos }\end{array}$ & $\begin{array}{c}\text { Número de } \\
\text { crianças batizadas }\end{array}$ & $\begin{array}{c}\text { Número de pais } \\
\text { incógnitos }\end{array}$ & $\begin{array}{c}\text { \% de pais } \\
\text { incógnitos }\end{array}$ \\
\hline $\begin{array}{l}\text { João Rodrigues } \\
\text { de Macedo }\end{array}$ & Contratador & 15 & 3 & 20,0 \\
\hline $\begin{array}{l}\text { Francisco de P. F. } \\
\text { de Andrada }\end{array}$ & Tenente Coronel & 8 & 1 & 12,5 \\
\hline $\begin{array}{l}\text { Rodrigo José } \\
\text { de Menezes }\end{array}$ & Governador & 11 & 0 & - \\
\hline $\begin{array}{l}\text { Luís da Cunha } \\
\text { Menezes }\end{array}$ & Governador & 23 & 0 & - \\
\hline
\end{tabular}

Fonte: Banco de Dados da Paróquia de Nossa Senhora do Pilar do Ouro Preto. Casa dos Contos.

$\mathrm{Na}$ análise do, por assim dizer, "nível de elitismo" do compadrio, outro desdobramento possível diz respeito às 'comadres' — ou seja, às mães das crianças batizadas. Apesar das possíveis negligências cometidas por párocos e seus auxiliares, a maioria não deixou de registrar os títulos sociais das mulheres que participaram na cerimônia do batismo. Nesse sentido, a designação 'Dona' (feminino de 'Dom') é um importante indicador da 'fidalguia' femini$\mathrm{na},{ }^{22}$ sendo o termo usado principalmente entre mulheres brancas da elite. $\mathrm{Na}$ Tabela 4, novamente constata-se uma forte diferença entre o comportamento dos governadores e o comportamento registrado entre membros da elite local. Em casos-limites, registram-se ocorrências de laços de compadrio do contratador com "pardas forras", como aquelas que o envolveram com Vitoriana Maria Guedes e Genovesa Rosa. 
Tabela 4

Mães com títulos sociais, paróquia de N. Sra. do Pilar de Vila Rica, 1777-1789

\begin{tabular}{lcccc}
\hline Padrinhos & $\begin{array}{c}\text { Condição social } \\
\text { dos padrinhos }\end{array}$ & $\begin{array}{c}\text { Número de } \\
\text { crianças batizadas }\end{array}$ & $\begin{array}{c}\text { Número de mães } \\
\text { das crianças } \\
\text { com títulos }\end{array}$ & $\begin{array}{c}\text { \% de mães } \\
\text { das crianças } \\
\text { com títulos }\end{array}$ \\
\hline $\begin{array}{l}\text { João Rodrigues } \\
\text { de Macedo }\end{array}$ & Contratador & 15 & 3 & 20,0 \\
\hline $\begin{array}{l}\text { Francisco de P. F. } \\
\text { de Andrada }\end{array}$ & Tenente Coronel & 8 & 2 & 25,0 \\
\hline $\begin{array}{l}\text { Rodrigo José } \\
\text { de Menezes }\end{array}$ & Governador & 11 & 9 & 81,8 \\
\hline $\begin{array}{l}\text { Luís da Cunha } \\
\text { Menezes }\end{array}$ & Governador & 23 & 21 & 91,3 \\
\hline
\end{tabular}

Fonte: Banco de Dados da Paróquia de Nossa Senhora do Pilar do Ouro Preto. Casa dos Contos.

Tabela 5

Madrinhas da paróquia de Nossa Senhora do Pilar de Vila Rica, 1777-1789

$\begin{array}{ccccc}\text { Padrinhos } & \begin{array}{c}\text { Condição social } \\ \text { dos padrinhos }\end{array} & \begin{array}{c}\text { Número de } \\ \text { madrinhas }\end{array} & \begin{array}{c}\text { Número de } \\ \text { madrinhas } \\ \text { com títulos }\end{array} & \begin{array}{c}\% \text { de } \\ \text { madrinhas } \\ \text { com títulos }\end{array}\end{array}$

\begin{tabular}{lcccc}
\hline $\begin{array}{l}\text { João Rodrigues } \\
\text { de Macedo }\end{array}$ & Contratador & 13 & 9 & 69,2 \\
\hline $\begin{array}{l}\text { Francisco de P. F. } \\
\text { de Andrada }\end{array}$ & Tenente Coronel & 6 & 5 & 83,3 \\
\hline $\begin{array}{l}\text { Rodrigo José } \\
\text { de Menezes }\end{array}$ & Governador & 11 & 11 & 100 \\
\hline $\begin{array}{l}\text { Luís da Cunha } \\
\text { Menezes }\end{array}$ & Governador & 8 & 8 & 100 \\
\hline
\end{tabular}

Fonte: Banco de Dados da Paróquia de Nossa Senhora do Pilar do Ouro Preto. Casa dos Contos.

Além da mãe da criança, também se registravam os nomes e condições das madrinhas. Conforme pode ser observado na Tabela 5, das 57 atas selecionadas, 19 (33,3\%) não contam com madrinhas. Esse percentual ficaria ainda mais elevado se nele incluíssemos as "madrinhas por procuração", ou seja, daquelas que enviavam um homem como representante, não comparecendo 
ao batizado. Impossibilitadas de ocupar cargos públicos e sujeitas ao poder patriarcal dos pais, maridos e até mesmo dos filhos mais velhos, as “mães espirituais" muitas vezes eram preteridas.

Outro indicador de status é a 'legitimidade' do afilhado. Símbolo de integração social, o "sacramento do matrimônio" era almejado pela elite, pois consistia em fator de distinção social e uma garantia de sucessão dos bens patrimoniais. ${ }^{23} \mathrm{Na}$ Tabela 6 observa-se que os governadores não aceitaram ser padrinhos de crianças nascidas fora de uniões conjugais sacramentadas. $\mathrm{O}$ contratador e o tenente coronel, uma vez mais, apresentam comportamento diverso, aceitando o compadrio com mães solteiras ou então afilhados que haviam sido abandonados à porta dos domicílios de Vila Rica.

\section{Tabela 6}

Legitimidade dos batizandos, paróquia de N. Sra. do Pilar, Vila Rica, 1777-89

\begin{tabular}{lccccc}
\hline Padrinhos & $\begin{array}{c}\text { Número de } \\
\text { crianças } \\
\text { batizadas }\end{array}$ & $\begin{array}{c}\text { Número de } \\
\text { crianças } \\
\text { legítimas }\end{array}$ & $\begin{array}{c}\text { Número de } \\
\text { das crianças } \\
\text { ilegítimas }\end{array}$ & $\begin{array}{c}\text { Número de } \\
\text { crianças } \\
\text { expostas }\end{array}$ & \% de pais \\
\hline $\begin{array}{l}\text { João Rodrigues } \\
\text { de Macedo }\end{array}$ & 15 & 10 & 3 & 2 & 66,6 \\
\hline $\begin{array}{l}\text { Francisco de P. F. } \\
\text { de Andrada }\end{array}$ & 9 & 7 & 2 & - & 77,7 \\
\hline $\begin{array}{l}\text { Rodrigo José } \\
\text { de Menezes }\end{array}$ & 11 & 11 & - & - & 100 \\
\hline $\begin{array}{l}\text { Luís da Cunha } \\
\text { Menezes }\end{array}$ & 23 & 23 & - & & - \\
\hline
\end{tabular}

Fonte: Banco de Dados da Paróquia de Nossa Senhora do Pilar do Ouro Preto. Casa dos Contos.

Nos assentos de batismos, a cor era uma forma de classificação social. Esse item era indicado apenas nos casos de pardos e negros. Os bebês sem indicação de cor eram socialmente considerados 'brancos'. Ao analisarmos a Tabela 7 , observamos que o número de batizandos dessa categoria é bastante elevado. Contudo, isso não exclui a possibilidade de comportamentos diferentes. Cabe lembrar que, enquanto o contratador e o tenente coronel aceitaram ser padrinhos de alguns meninos e meninas 'pardos', o mesmo não foi registrado entre os governadores. Também é digna de nota a ausência de 'negros' nas atas analisadas - população que constituía expressivo segmento so- 
cial de Vila Rica, mas que apresentava dificuldades em estabelecer laços de parentesco espiritual com a elite.

Tabela 7

Cor presumida dos batizandos, paróquia N. Sra. do Pilar, Vila Rica, 1777-1789

\begin{tabular}{lcccc}
\hline Padrinhos & $\begin{array}{c}\text { Número de } \\
\text { Batismos }\end{array}$ & $\begin{array}{c}\text { Número de } \\
\text { Brancos }\end{array}$ & $\begin{array}{c}\text { Número de } \\
\text { Pardos }\end{array}$ & $\begin{array}{c}\% \text { de } \\
\text { Brancos }\end{array}$ \\
\hline $\begin{array}{l}\text { João Rodrigues } \\
\text { de Macedo }\end{array}$ & 15 & 12 & 3 & 80,0 \\
\hline $\begin{array}{l}\text { Francisco de P. F. } \\
\text { de Andrada }\end{array}$ & 9 & 5 & 3 & 55,5 \\
\hline $\begin{array}{l}\text { Rodrigo José } \\
\text { de Menezes }\end{array}$ & 11 & 11 & - & 100 \\
\hline $\begin{array}{l}\text { Luís da Cunha } \\
\text { Menezes }\end{array}$ & 23 & 23 & - & $10-0$ \\
\hline
\end{tabular}

Fonte: Banco de Dados da Paróquia de Nossa Senhora do Pilar do Ouro Preto. Casa dos Contos.

Ao analisarmos os laços estabelecidos através do compadrio, observamos que as escolhas — salvo algumas exceções — tendiam a se restringir a um grupo social bastante restrito. Isso levava à constante reiteração do vínculo, desfeito pela morte prematura da criança - algo bastante freqüente na época - , ou pelo retorno do governador ao mundo metropolitano. Um caso típico dessa postura foi a seqüência de batizados dos filhos do Doutor Gregório Pereira Soares de Albergaria e de sua esposa, Dona Leonor Francisca Xavier de Souza e Albergaria: os dois primeiros filhos desse casal foram apadrinhados pelo governador Rodrigo José de Menezes, e os três seguintes pelo governador Luís da Cunha Menezes.

As marcas de diferenciação da hierarquia social se estendiam aos templos ou casas - com oratórios provisionados ${ }^{24}$ - onde se realizavam as cerimônias do batismo. Como podemos notar na Tabela 8, mais de 80 por cento dos batismos de nossa amostragem foram realizados na Igreja Paroquial de Nossa Senhora do Pilar do Ouro Preto. Essa matriz, considerada "Igreja Mãe", reunia em si a notoriedade da pompa barroca, desejada pelas famílias da elite. Porém, cabe assinalar que, na época, a noção de 'templo' era bastante complexa. A instituição não se reduzia ao prédio da igreja, incluindo também locais externos, como eram os casos das capelas e oratórios subordinados à paróquia matriz. 
Tabela 8

Locais onde foram realizadas as cerimônias de batismo na paróquia de Nossa Senhora do Pilar de Vila Rica, 1777-1789

\begin{tabular}{lcccc}
\hline Padrinhos & Batismos & $\begin{array}{c}\text { Igreja do } \\
\text { Pilar }\end{array}$ & $\begin{array}{c}\text { Oratórios } \\
\text { Particulares }\end{array}$ & $\begin{array}{c}\text { Capela } \\
\text { do Palácio }\end{array}$ \\
\hline $\begin{array}{l}\text { João Rodrigues } \\
\text { de Macedo }\end{array}$ & 15 & 15 & - & - \\
\hline $\begin{array}{l}\text { Francisco de P. F. } \\
\text { de Andrada }\end{array}$ & 9 & 9 & - & - \\
\hline $\begin{array}{l}\text { Rodrigo José } \\
\text { de Menezes }\end{array}$ & 11 & 3 & - & 1 \\
\hline $\begin{array}{l}\text { Luís da Cunha } \\
\text { Menezes }\end{array}$ & 23 & 20 & 2 & \\
\hline
\end{tabular}

Fonte: Banco de Dados da Paróquia de Nossa Senhora do Pilar do Ouro Preto. Casa dos Contos.

Dessa forma, na sociedade colonial, o local de ocorrência do batizado tinha um significado importante. A Capela de Nossa Senhora da Conceição do Palácio do Governador simbolizava o mais alto nível de poder. Conforme podemos observar na Tabela 8, o governador Rodrigo José de Menezes e, seu sucessor, Luís da Cunha Menezes, seguiam códigos condizentes, embora de forma diferenciada. O primeiro batizou onze meninos e meninas, sendo oito das cerimônias realizadas na capela palaciana, o que sugere serem mais intimistas as relações de D. Rodrigo com a elite local. Em contraposição, D. Luís aparece como um governante mais seletivo no que tange à intimidade, perfil confirmado por testemunho de Tomás Antônio Gonzaga, que o descreve como um homem de "pouca fala" e de "estilo duro".

O local do batismo também informa sobre as variações do prestígio social e político. O Tenente Coronel Francisco de Paula Freire de Andrada viu no batismo a possibilidade de estreitar laços de compadrio com o governador. Desse modo, em nosso levantamento, observamos que dois filhos de Freire de Andrada tiveram como padrinho o governador Luís da Cunha Menezes. O primeiro batizado foi realizado na Igreja Matriz de Nossa Senhora do Pilar, e o segundo na Capela de Nossa Senhora da Conceição do Palácio. Num terceiro batismo - em que o governador não aparece como padrinho e que ocorreu em 6 de dezembro de 1789 —, a situação registrada é bem diferente. Por esta época, Francisco de Paula Freire de Andrada estava sendo processado pela Coroa portuguesa, por seu envolvimento na Inconfidência Mineira. 
Não por acaso, a cerimônia de batizado do filho acabou sendo realizada na humilde Capela de Nossa Senhora do Chiqueiro do Alemão...

\section{REDES DE COMPADRIO}

Como vimos, os assentos de batismos trazem preciosas informações a respeito do parentesco espiritual. Cabe agora esboçar como as redes de compadrio funcionavam, indicando também sua dimensão política. Para entendermos isso, é necessário recorrermos à noção de "intermediário social". Caso o parentesco espiritual envolvesse a autoridade máxima da capitania, o compadre podia ter acesso ao rei, no sentido de conquistar graças e mercês, ou, mais simplesmente, ter uma petição sua atendida. Porém, os compadres menos poderosos serviam de intermediários do governador junto à população livre e pobre, transferindo parte da ascendência que tinham sobre ela à autoridade reinol. Dessa forma era criada uma rede política e social que podia começar entre humildes ex-escravas e terminar em famílias reais européias.

No sentido de ilustrar essa situação, selecionamos dois casos. O primeiro deles envolveu um governador e, o segundo, uma parda forra. Os dados do primeiro caso estão sintetizados no Quadro 1. Nele não foi possível identificar a ocupação de todos os padrinhos, mas somente daqueles que constam na correspondência do governo de Minas Gerais com o Conselho Ultramarino. $\mathrm{O}$ dado mais surpreendente desse levantamento diz respeito ao pequeno intervalo entre a chegada do governador e a sua presença na cerimônia batismal. Segundo a documentação oficial, D. Luís da Cunha Menezes assumiu o governo mineiro em 20 de outubro de $1783 .{ }^{26}$ Ora, como foi possível observar, no dia 28 de agosto de 1783, portanto antes mesmo de assumir o referido cargo, ele aceitou ser padrinho de um filho do Tenente Coronel Francisco de Paula Freire de Andrada. Como se tratava de um descendente de ex-governador de Minas, é possível suspeitar que o tenente coronel tivesse algum contato prévio com o novo governador. A seqüência de compadrios sugere, porém, que o estabelecimento precoce de laços de parentesco espiritual, pelo menos no caso de D. Luís, foi norma e não exceção. 


\section{Quadro 1}

Fragmento da rede de compadrio do governador Luís da Cunha Meneses, 1783-1788

\begin{tabular}{|lcl|}
\hline Compadres & Data do $1^{\mathbf{0}}$ compadrio & Ocupação do compadre \\
\hline $\begin{array}{l}\text { Tenente Coronel Francisco } \\
\text { de P. F. de Andrada }\end{array}$ & $28 / 08 / 1783$ & $\begin{array}{l}\text { Comandante do Regimento da } \\
\text { Cavalaria Paga de Minas Gerais }\end{array}$ \\
\hline $\begin{array}{l}\text { Capitão José de Vasconcelos } \\
\text { Perada e Souza }\end{array}$ & $26 / 10 / 1783$ & $\begin{array}{l}\text { Comandante dos Destacamentos } \\
\text { das Terras Diamantíferas } \\
\text { do Serro Frio }\end{array}$ \\
\hline $\begin{array}{l}\text { Doutor Gregório Pereira } \\
\text { Soares de Albergaria }\end{array}$ & $30 / 11 / 1783$ & $\begin{array}{l}\text { Escrivão da Receita e Despesa } \\
\text { da Real Casa de Fundição } \\
\text { de Vila Rica }\end{array}$ \\
\hline $\begin{array}{l}\text { Tenente Carlos } \\
\text { Castro Monteiro }\end{array}$ & $20 / 09 / 1785$ & $\begin{array}{l}\text { Tenente da Cavalaria do } \\
\text { Regimento de Vila Rica }\end{array}$ \\
\hline Capitão José Luís Saião & $07 / 05 / 1786$ & $\begin{array}{l}\text { Secretário do Governo da } \\
\text { Capitania de Minas Gerais }\end{array}$ \\
\hline $\begin{array}{l}\text { Tenente Tomás Joaquim } \\
\text { de Almeida Front }\end{array}$ & $12 / 11 / 1786$ & $\begin{array}{l}\text { Alferes do Regimento do } \\
\text { Rio das Mortes }\end{array}$ \\
\hline Capitão Marçal José de Araújo & $25 / 11 / 1787$ & $\begin{array}{l}\text { Porteiro da Junta de } \\
\text { Administração da Fazenda } \\
\text { Real de Minas Gerais }\end{array}$ \\
\hline
\end{tabular}

Fonte: Boschi, C. C. (Org.) Inventário dos manuscritos avulsos relativos a Minas Gerais existentes no Arquivo Histórico Ultramarino - Lisboa. Índices de Júnia Ferreira Furtado. Belo Horizonte: Fundação João Pinheiro, Centro de Estudos Históricos e Culturais, 1998.

Um mês e dez dias após ter assumido o cargo, D. Luís passou a contar com três compadres, atuando em Vila Rica e em terras diamantíferas do Serro Frio. Nos quatro anos seguintes, suas relações de compadrio - aqui estudadas, cabe lembrar, a partir de uma única paróquia — passaram a cobrir as principais áreas econômicas e militares da capitania de Minas Gerais. Como se vê, o "parentesco espiritual” permitia a formação imediata de redes familiares. Graças ao caráter de fronteira das Minas Gerais do século XVIII — região povoada pouco antes e que constantemente recebia novos imigrantes - , esse tipo de vínculo desempenhava um papel fundamental, permitindo até mesmo um ensaio de "poder oligárquico", tema que também começa a ser estudado através da correspondência colonial. ${ }^{27}$ 
As relações clientelares da elite, geradas através do compadrio, com certeza envolviam as camadas dominadas. No Organograma 1, indicamos um fragmento da rede de compadrio da parda forra Vitoriana Maria Guedes. Em 22 de maio de 1781, ela se tornou comadre de João Rodrigues de Macedo. Tratava-se, como se pode imaginar, de uma aliança muito importante, que transformava a forra em uma poderosa 'intermediária' na comunidade de libertos e escravos de Vila Rica. ${ }^{28}$

Tendo em vista que esse caso diz respeito a uma mãe solteira, e que o pai da criança aparece na ata como "incógnito", poderíamos especular se esse compadrio serviu para camuflar uma paternidade ilegítima do contratador. Sem dúvida essa situação é plausível. No entanto, uma análise mais atenta do organograma mostra que a forra Vitoriana também estabeleceu laços de compadrio com mulheres da elite, como foi o caso do vínculo criado com D. Francisca Antonia Xavier de Souza.

Ora, ao reconstituirmos a genealogia de D. Francisca Antonia Xavier de Souza, identificamos uma irmã, ${ }^{29}$ esposa do já mencionado Doutor Gregório Pereira Soares de Albergaria. Havia, dessa forma, vínculos entre os indivíduos arrolados no Quadro 1 e os presentes no Organograma 1. Caso voltemos nossa análise somente para o casal indicado, veremos que a forra Vitoriana, por meio da comadre D. Francisca, podia ter acesso aos governadores de Minas Gerais. Mais ainda: D. Rodrigo foi um dos raros governadores que veio acompanhado pela mulher: D. Maria José de Eça e Bourbon, que descendia de linhagens presentes nas casas reinantes de Portugal, Espanha, França e até mesmo da Polônia... ${ }^{30}$ Ao aceitar ser madrinha da filha de Vitoriana Maria Guedes, D. Francisca, indiretamente, estendeu os laços sociais da ex-escrava ao topo da hierarquia social de Vila Rica. 
Organograma 1 - Fragmento da rede de compadrio de Vitoriana Maria Guedes, parda forra, 1781-1785

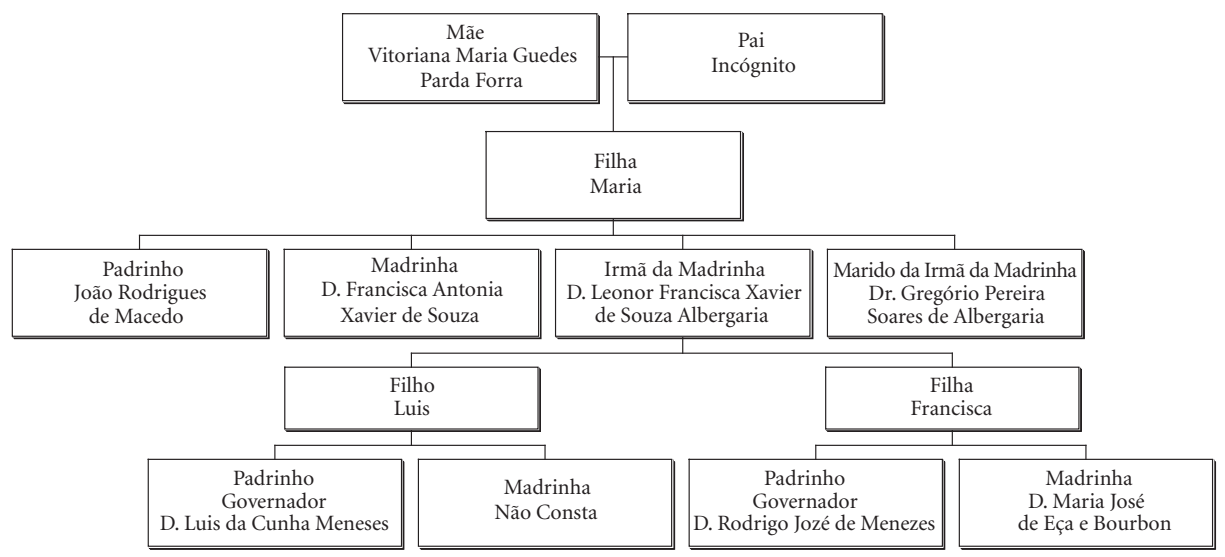

Fonte: Banco de Dados da Paróquia de Nossa Senhora do Pilar do Ouro Preto. Casa dos Contos.

As redes de compadrio, dessa maneira, potencializavam o universo de “intermediários sociais", em parte também neutralizando as tendências elitistas engendradas pelo sistema escravista. No entanto, é necessário evitar mistificações. O Tenente Coronel Francisco de Paula Freire de Andrada, embora filho e compadre de governadores, não escapou de ser perseguido politicamente e exilado. De qualquer forma, por mais amargo que fosse esse destino, era ele melhor do que a forca. Sintomaticamente, na documentação analisada, nenhum membro da elite de Vila Rica elegeu o Alferes Joaquim José da Silva Xavier como padrinho. Nas atas da Igreja de Nossa Senhora do Pilar do período analisado, Tiradentes é mencionado apenas duas vezes, uma delas como suposto pai de Joaquina, filha de Antonia Maria do Espírito Santo, mulher solteira, que o processava por quebra de promessa de casamento:

Aos trinta e um dias do mês de agosto de mil setecentos e oitenta e seis anos nesta igreja matriz de Nossa Senhora do Pilar de Vila Rica do Ouro Preto com licença paroquial o Padre Pantaleão da Silva Ramos Presbítero secular batizou e pôs os santos óleos a Joaquina filha natural de Antônia Maria do Espírito Santo, e de pai que se diz ser o Alferes Joaquim José da Silva Xavier, todos desta freguesia. Foi Padrinho Domingos de Abreu Vieira, Solteiro, morador na freguesia de Antônio Dias desta vila, de que fiz este assento.

Coadjutor Antônio Ribeiro de Azevedo ${ }^{31}$ 


\section{NOTAS}

${ }^{1}$ As fontes de nossa pesquisa dizem respeito aos assentos de batismos da Igreja Matriz de Nossa Senhora do Pilar do Ouro Preto, custodiados pelo Museu Casa dos Contos de Ouro Preto, e que se encontram sobre o suporte de microfilmes, rolo 103, v.492, rolo 104, v.492 e 495. Tal material se encontra também no Banco de Dados da Paróquia de Nossa Senhora do Pilar do Ouro Preto, organizado pela professora Adalgisa Arantes Campos (UFMG) e financiado pela Fapemig.

${ }^{2}$ Eis alguns trabalhos a respeito do tema: GUDEMAN \& SCHWARTZ. Purgando o pecado original: compadrio e batismo de escravos na Bahia no século XVIII. In: REIS, J. J. (Org.) Escravidão e invenção da liberdade. Estudos sobre o negro no Brasil. São Paulo: Brasiliense, 1988, p.33-59; SCHWARTZ, Stuart. Abrindo a roda da família: compadrio e escravidão em Curitiba e na Bahia. In: Escravos, roceiros e rebeldes. Bauru: Edusc, 2001, p.263-92; NEVES, Maria de Fátima R. Ampliando a família escrava: compadrio de escravos em São Paulo do século XIX. In: História e população: estudos sobre a América Latina. Belo Horizonte: Seade/Abep/Iuspp, 1990, p.240-9; BOTELHO, Tarcísio Rodrigues. Batismo e compadrio de escravas: Montes Claros (MG), século XIX. Locus, 1997, v.3, n.1, p.108-15; GOLDSCHMIDT, Eliana Maria Réa. Compadrio de escravos em São Paulo colonial. Reunião da SBPH, VIII, 1989, Anais..., 1989, p.241-6; BRUGGER \& KJERVE. Compadrio: relação social e libertação espiritual em sociedades escravistas (Campos, 1754-1766). Estudos Afro-Asiáticos, 1991, n.20, p.224-38; RIOS, Ana Maria Lugão. The politics of kinship: compadrio among slaves in nineteenth-century Brazil. The history of family, 2000, v.5, n.3, p.291-3; GÓES, José Roberto. O cativeiro imperfeito: um estudo sobre a escravidão no Rio de Janeiro da primeira metade do século XIX. Vitória (ES): Secretaria de Estado da Educação, 1993; FLORENTINO \& GOES. A paz das senzalas: famílias escravas e tráfico atlântico, Rio de Janeiro, c. 1790-1850. Rio de Janeiro: Civilização Brasileira, 1997; FREIRE, Jonis. Batismo e compadrio em uma freguesia escravista: Senhor Bom Jesus do Rio Pardo (MG), 1838-1888. Dissertação (Mestrado) — Unesp (Franca), 2004; ANDRADE, Vitória Fernanda Schettini. Batismo e apadrinhamento de filhos de mães escravas. São Paulo do Muriaé (1852-1888). Dissertação (Mestrado) — Universidade Severino Sombra, 2006.

${ }^{3}$ Uma inovadora análise dos testamentos, como fonte para o estudo do compadrio, é proposta por FARIA, Sheila de Castro. A colônia em movimento: fortuna e família no cotidiano colonial. Rio de Janeiro: Nova Fronteira, 1998, p.216.

${ }^{4}$ SILVA, Vera Alice Cardoso. Aspectos da função política das elites na sociedade colonial brasileira: o "parentesco espiritual" como elemento de coesão social. Varia História, 2004, v.31, p.97-119.

${ }^{5}$ Conforme afirmam especialistas: “De facto, conceber mercês ao 'mais amigo' eram situações sociais quotidianas e corporizavam a natureza mesma das estruturas sociais, sendo, portanto, vistas como 'normais'". XAVIER \& HESPANHA. As redes clientelares. In: MATTOSO, José (Dir.) História de Portugal: o Antigo Regime. Lisboa: Ed. Estampa, 1993, v.4, p.381-93.

${ }^{6}$ Constituições Primeiras do Arcebispado da Bahia, Título X, XI, 1707. 
${ }^{7}$ Constituições Primeiras do Arcebispado da Bahia, Título XII, 1707.

${ }^{8}$ RAMOS, Donald. Teias sagradas e profanas: o lugar do batismo e compadrio na sociedade de Vila Rica durante o século do ouro. Varia História, 2004, v.31, p.50.

${ }^{9}$ De acordo com as Constituições Primeiras do Arcebispado da Bahia, o batismo dos inocentes deveria ocorrer no prazo máximo de oito dias após o nascimento, independentemente da condição social do batizando. Caso contrário, os pais ou responsáveis pelo inocente incorreriam em pena pecuniária de 10 tostões para a fábrica (tesouraria) da igreja matriz, e, a cada oito dias de atraso, a pena deveria dobrar. Tendo em vista a fugacidade da vida do homem do Setecentos, e conseqüentemente a elevada mortalidade infantil e adulta, os pais ou responsáveis pela criança cuidavam para que esse sacramento fosse realizado o mais rápido possível. A morte de um bebê pagão tinha dois agravantes: o primeiro recaía sobre o morto, o qual era condenado à danação eterna. Já o segundo agravante recaía sobre os pais ou responsáveis, que amargavam o pecado e o remorso de não ter contribuído para a salvação de uma alma.

${ }^{10} \mathrm{O}$ assento referido encontra-se no Arquivo Casa dos Contos de Ouro Preto, séries de batismo, Igreja Matriz do Pilar de Ouro Preto, rolo 103, v.492. Nesse documento, como nos seguintes, a ortografia foi atualizada.

${ }^{11}$ SIGNORINI, Ítalo. Padrini e compadri: un'analisi antropologica della parentela spirituale. Torino: Loescher, 1981, p.19.

${ }^{12}$ MAXWELL, Kenneth. A Devassa da Devassa: A Inconfidência Mineira: Brasil e Portugal 1750-1808. Rio de Janeiro: Paz e Terra, 1978, p.53.

${ }^{13}$ Nuno Gonçalo Monteiro amplia o conceito da nobreza lusitana, mostrando suas diversas variantes, que podiam ser de Sangue, Civil e Política. MONTEIRO, Nuno Gonçalo. Poder senhorial, estatuto nobiliárquico e aristocracia. In: MATTOSO, José (Dir.) História de Portugal: o Antigo Regime. Lisboa: Ed. Estampa, 1993, v.4, p.333-79.

${ }^{14}$ JARDIM, Márcio. A inconfidência mineira: uma síntese factual. Rio de Janeiro: Ed. Biblioteca do Exército, 1989, p.164.

${ }^{15}$ Ibidem, p. 47-8.

${ }^{16}$ SOUZA, Laura de Mello e. Norma e conflito: aspectos da história de Minas no século XVIII. Belo Horizonte: Ed. UFMG, 1999, p.189.

${ }^{17}$ BARBOSA, Waldemar. História de Minas. Belo Horizonte: Ed. Comunicação, 1979, v.3, p.616.

${ }^{18}$ Cabe lembrar que, em nossa amostragem, há um forte risco de subregistro, pois não levamos em conta os dados da outra paróquia urbana de Vila Rica - a de Nossa Senhora da Conceição de Antonio Dias; também não levamos em conta importantes paróquias de localidades vizinhas, como a da Sé de Mariana, sede do bispado mineiro. Isso para não mencionarmos, ainda, os casos de uso de "procuração", o que permitia ao governador ser padrinho de crianças em paróquias bastante distantes de Vila Rica.

${ }^{19}$ Carta de José Felizardo da Costa ao Governador D. Manoel de Portugal, Rio Pardo de Minas, 8 de junho de 1814. Arquivo Público Mineiro, Cód. CC, Gaveta E-5, Rolo 508, M. 
0994, P. 10520. Cabe lembrar que esse documento faz referência à “procuração" e diz respeito a um morador em localidade bastante distante de Vila Rica.

${ }^{20}$ RAMOS, Donald. Teias sagradas e profanas: o lugar do batismo e compadrio na sociedade de Vila Rica durante o século do ouro. Varia História, 2004, v.31, p.60.

${ }^{21}$ Estudos com base na documentação da paróquia de Nossa Senhora do Pilar revelam que, entre 1712 e 1810, o percentual de filhos ilegítimos de mulheres livres era da ordem de $21,2 \%$; entre as mulheres forras esse número aumentava para 78,1\%; entre as escravas tal percentual atingia $88,9 \%$. O comportamento dos governadores refletia, dessa forma, a hierarquização social definida pelo sacramento do matrimônio. LIBBY \& BOTELHO. Filhos de Deus: batismo de crianças legítimas e naturais na paróquia de Nossa Senhora do Pilar de Ouro Preto, 1712-1810. Varia História, 2004, v.31, p.81.

${ }^{22}$ GODINHO, Vitorino Magalhães. Estrutura da Antiga Sociedade Portuguesa. Lisboa: Arcádia, 1980, p.73-4.

${ }^{23}$ LEWIN, Linda. Repensando o patriarcado em declínio: de "pai incógnito" a "filho ilegítimo" no direito sucessório brasileiro no século XIX. Ler História, n.29, 1995, p.120-9.

${ }^{24}$ Entende-se por oratórios privilegiados aqueles que recebiam a concessão de Roma para celebrarem o Santo Sacrifício da Missa. Tal concessão era feita apenas a uma pessoa da casa, mediante a abertura de um processo feito no Bispado que circunscrevia a freguesia de moradia do solicitante. Para se obter a concessão era preciso pertencer à fidalguia local. Tal posição social era averiguada no decorrer do processo quando se colhia o depoimento do solicitante do Breve e das testemunhas fidedignas que o conheciam. A estes era feita uma inquirição para se investigar: se o impetrante, ou alguém de sua casa, já havia sido agraciado com outra concessão de oratório, e se o beneplácito foi alcançado licitamente. Este pedido de concessão de Breve era enviado à Santa Sé de Roma, e só depois de receber seu deferimento o Reverendo Provisor, da freguesia do requerente, expedia um mandato de visita ao Pároco responsável pela respectiva paróquia, com o intuito de averiguar se o local reservado para se instalar o oratório era privado de circulação de uso doméstico, se estava ornado e paramentado decentemente com os ornamentos das quatro cores, assim como se tinha pedra d'ara e alfaias, indispensáveis à celebração do Culto Divino. Essa concessão era paga e deveria ser renovada anualmente. As normas para obtenção de Breves provisionados podem ser encontradas no Arquivo Eclesiástico da Arquidiocese de Mariana. Por exemplo: a concessão de Breve localizada na Pasta 1243, Período 1789 a 1793, Sabará.

${ }^{25}$ FURTADO, João Pinto. O manto de Penélope: história, mito e memória da Inconfidência Mineira de 1788-9. São Paulo: Companhia das Letras, 2002, p.153.

${ }^{26}$ CALMON, Pedro. História do Brasil. 3.ed. Rio de Janeiro: J. Olympio, 1971, v.4, p.1337.

${ }^{27}$ BOSCHI, Caio. Administração e administradores no Brasil pombalino: os governadores da Capitania de Minas Gerais. Tempo, n.13, 2002, p.77-109.

${ }^{28}$ Em Vila Rica, ao longo do século XVIII, a população forra aumentou de forma intensa, Para se ter idéia disso, basta mencionarmos que, entre 1719 e 1723, a paróquia vizinha a do Pilar registrou apenas 3 óbitos de forros, em um total de 387 mortes; cinqüenta anos mais tarde, foram registrados 142 óbitos de libertos, em um montante de 953 mortes; e, 
entre 1804 e 1808, esse número aumentou para 180 óbitos de forros, em um contexto de 797 mortes. Portanto, se considerarmos o número de óbitos como um indicador da evolução demográfica, concluiremos que, no início do século XVIII, os forros representavam 0,7\% da população da paróquia de Antonio Dias de Ouro Preto; ao passo que, entre 1769 e 1773, essa presença havia aumentado para $14,9 \%$ e, no início do século XX, ela atingia a casa dos 22,5\%. Um fantástico crescimento de 3.200 por cento! COSTA, Iraci del Nero da. Vila Rica: população (1719-1826). São Paulo: IPE/USP,1979. Anexos.

${ }^{29}$ Disponível em genealogia.sapo.pt, acesso em 1.02.2005.

${ }^{30}$ Disponível em genealogia.sapo.pt; acesso em 1.02.2005.

${ }^{31}$ A segunda menção é a de Ana, filha legítima de Emerenciana Gomes da Silva e Faustino Vieira de Souza, batizada na Matriz do Pilar em 22 de janeiro de 1787, sendo padrinhos: Alferes Joaquim José da Silva Xavier e Dona Ana Joaquina de São José, Casa dos Contos, Rolo 103, v.492, f.349. 